\title{
Fruit morphological attributes to assess genetic diversity in jujube (Ziziphus mauritiana L.) germplasm of Bahawalpur
}

Ishtiaq Ahmad ${ }^{1 *}$, Muhammad Nafees ${ }^{1}$, Irfan Ashraf $^{1}$, Maryam², Jameel M. Al-Khayri ${ }^{3}$, Malik Muhammad Yousaf ${ }^{4}$, Bashir Ahmad ${ }^{4}$ and Rahmatullah Qureshi ${ }^{5}$

1. University College of Agriculture \& Environmental Sciences, Islamia University of Bahawalpur,-Pakistan

2. MNS University of Agriculture Multan-Pakistan

3. Department of Agricultural Biotechnology, College of Agriculture and Food Sciences, King Faisal University-

Saudi Arab

4. Arid Zone Research Institute, Bahawalpur, (PARC)-Pakistan

5. Department of Botany, Pir Mehr Ali Shah Arid Agriculture University, Rawalpindi-Pakistan

*Corresponding author's email: ishtiaq507@ gmail.com

Citation

Ishtiaq Ahmad, Muhammad Nafees, Irfan Ashraf, Maryam, Jameel M. Al-Khayri, Malik Muhammad Yousaf, Bashir Ahmad and Rahmatullah Qureshi. Fruit morphological attributes to assess genetic diversity in jujube (Ziziphus mauritiana L.) germplasm of Bahawalpur. Pure and Applied Biology. Vol. 5, Issue 4, pp921-926. http://dx.doi.org/10.19045/bspab.2016.50116

Received: 12/05/2016

Revised: 27/07/2016

Accepted: $20 / 08 / 2016$

Online First: 25/08/2016

\section{Abstract}

Genetic diversity plays a major role in varietal improvement of crops. The genus Ziziphus (jujube or ber) is an important fruit crop of arid zones consisting of above 100 species of deciduous or evergreen plants and shrubs widely scattered in the desert, tropical and subtropical areas. In Pakistan, several local and exotic accessions are being cultivated for fruit production. Jujube is neglected fruit crop in Pakistan with diminutive assessment of fruit morphological characters. In this study, 22 selected accessions were characterized based on various physico-morphological traits. The results proved broad genetic base in all 22 genotypes for various commercial traits. Fruits from the selected genotypes were assessed based on fruit weight, fruit length, seed weight, seed length, seed diameter, fruit pulp weight and total soluble solids (TSS). Highest variation $(7.22 \%$ ) was recorded in fruit weight which ranged from 6.08 to $37.64 \mathrm{~g}$ among the tested genotypes; however, least variation was recorded in seed weight. Strongest correlation of $r=0.99$ was measured between fruit and pulp weight with all 22 genotypes were clustered into three main classes with maximum variation of $163 \%$ within class $c$ followed by classes a and b with variation of 73.35 and $64.18 \%$ within the classes, respectively. Studied genotypes had broad genetic base with a high flow of characters among them, could be used in advanced breeding for varietal improvement programs.

Keywords: Physico-morphological characters; Cultivars; PC analysis; Correlation and cluster analysis

\section{Introduction}

The genus Ziziphus (jujube, also known as Ber) is an important member in the family Rhamnaceae. This genus consists of more than 100 species of trees and shrubs including deciduous and evergreen distributed in the tropics and subtropics [1]. It is believed that $Z$. mauritiana found in almost every continent of the world. This hardy species is easy to grow and can 
survive on a wide range of soils even in desert conditions. It is a prominent vegetation of India \& Pakistan deserts [2].

Present jujube varieties are the result of wide selection process in India and China and they created thrust for improvement and research [3]. In Pakistan, total area of jujube orchards is over 5425 ha with an annual production of about 28 thousand tones [4]. Nonetheless, only limited research work is available on fruit morphology [1]. There is no serious attempt made on the classification of Ber varieties on the basis of fruit setting habit, fruit morphology and blooming time even though many varieties are being grown in Pakistan [5]. Ber varieties were identified on basis of fruit characters including the following fruit traits: fruit with a distinctly pointed apex, fruit with a slightly pointed apex, fruit with a round apex, and fruit apex round with a depression [6]. The size of fruit varies from chary to plum size depending on cultivar [7]. There is physio-chemical difference among the Ber verities [8]. Jujube germplasm characterization, evaluation and improvement are fundamentally based on morpho-physiological traits. The lack of breakthrough is a consequence of underutilization of genetic variability for superior quality and high yield potential [9]. Ber is among the neglected fruit crops in Pakistan. Recently, demand for its nutritive fruit is steadily increasing. This demand for Ber attracted scientists to understand basic characteristics of fruit morphology of different available accessions in the country. Therefore, the present study offers the needed information for consumers. The main objective of this study was to evaluate the morphological characters of fruit to assess the diversity of Ber in Pakistan and identify suitable promising accessions for trait improvement and breeding programs.

\section{Materials and methods}

Twenty two jujuba genotypes locally named as Bahawalpur selection-1 (BW_S1),
Bahawalpur selection-5 (BW_S5), Yazman Local (Yaz_L), Sabir-Wali (Sa_W), Foladi (FD), Kerala (KL), Alobukhara (Alo_B), Dil-Bahar (D_B), Imran Kerala (Im_Kl), Anokhi (Ak), Ghor (Ghor), Khubani (Khu), Akasha (Ak), Sofan (Sof), Dehli Sofaid (D_sd), AZRI-1 (Az_1), AZRI-2 (Az_2), Elachi (Ela), Imran-9 (Im_9), Imran-13 (Im_9), Mahmood Wali (Ma_Wa) and Imli (IMLI) were assessed in this study for fruit morphological characters. Jujuba germplasm repository was developed during 2000-2001 in the Regional Agriculture Research Station and the Arid Zone Agriculture Research Institute at Bahawalpur, Pakistan. The experimental plants were selected based on healthy appearance, plant size uniformity, and fruit production. Experimental plants were receiving uniform agronomic practices like fertilizer and irrigation as per horticultural standards. Twenty five mature fruits, uniformly shaped and free of insect and pests attack were randomly collected from five plants of each variety. Total number of fruits (25) collected from each plant were weighed to record the average fruit weight of each plant separately as independent replications in each genotype. Average seed weight of 25 fruits was also recorded. Ten out of 25 fruits fruit were randomly selected to measure fruit and seed length $(\mathrm{cm})$, diameter $\left(\mathrm{cm}^{2}\right)$, pulp weight $(\mathrm{g})$ and total soluble solids (TSS) $\left(\right.$ Brix $\left.^{\circ}\right)$. Digital weighing balance (KDC, TH- 500, capacity $5000 \mathrm{~g} \times 1 \mathrm{~g}$ ) and vernier caliper (KBD-MT 0014) were used to record fruit and seed characters; whereas, the total soluble solids of five fruits in each genotype, was measured using digital refractometer (ATAGO RX 5000, Japan Development Assistance).

\section{Statistical analysis}

The study was conducted as a completely randomized single factor design. The main factor is the variety at 22 levels (22 varieties) with 5 replications (5 plants). 
Different fruit morphological observations were recorded and subjected to statistical analysis using EXLSTAT (2015) software.

\section{Results and discussion}

\section{Summary of statistic and correlation of} traits in PCA analysis

Multivariate analysis of collected data showed highest variation $(7.22 \%)$ in fruit weight ranged from 6.08 to $37.64 \mathrm{~g}$ among the tested jujube genotypes. This was followed by pulp weight, seed length and fruit length as shown in Table 1. The least variation was recorded in seed weight in all 22 genotypes. Correlation matrix values of studied traits in all 22 genotypes showed strongest correlation of 0.99 between fruit weight and pulp weight. This was followed in fruit diameter and pulp weight (0.964) and fruit weight and fruit diameter (0.962). There is negligible correlation for TSS with all other traits, however, Fruit and seed length had high negative correlation with TSS (Table 2).

The results proved broad genetic base of all 22 genotypes for various commercial traits like fruit weight, pulp weight and seed length, moreover, strong correlation was also recorded among these traits. Ketipearachchi et al. [10] proved that the accessions in Ziziphus mauritian had high range of fruit weight (10.38-85.83 g) and TSS (1.6 to $16 \mathrm{Brix}^{\circ}$ ) with good fruit quality growing in desert zones of Sri Lanka (Dry Dambulla, Hambantota and Putlam), however, fruit weight is quite low (6.08 to 37.64g) with good TSS values 7.95 to 17.36 Brix $^{\circ}$ in our desert zones of Bahawalpur. This low production and small fruit size need improvement in breeding and production technology. These results are in line with the findings of [9], who reviewed jujube plant growing in China.

Table 1. Morphological diversity among 22 genotypes of jujube at $(P \leq 0.05)$

\begin{tabular}{|l|l|l|l|}
\hline Variable & \multicolumn{1}{|c|}{ Minimum } & \multicolumn{1}{c|}{ Maximum } & \multicolumn{1}{c|}{ Mean } \\
\hline Fruit weight $(\mathbf{g})$ & $6.084 \pm 7.22$ & $37.644 \pm 7.22$ & $18.156 \pm 7.22$ \\
\hline Fruit length $(\mathbf{c m})$ & $22.234 \pm 5.55$ & $47.988 \pm 5.55$ & $37.658 \pm 5.55$ \\
\hline Fruit diameter(cm) & $21.256 \pm 4.98$ & $40.252 \pm 4.98$ & $29.545 \pm 4.98$ \\
\hline Seed weight $(\mathbf{g})$ & $0.98 \pm 0.44$ & $1.994 \pm 0.44$ & $0.946 \pm 0.44$ \\
\hline Seed length $(\mathbf{c m})$ & $11.34 \pm 5.78$ & $26.322 \pm 5.78$ & $20.244 \pm 5.78$ \\
\hline Seed diameter $(\mathbf{c m})$ & $4.67 \pm 2.40$ & $12.008 \pm 2.4$ & $8.413 \pm 2.4$ \\
\hline Pulp weight $(\mathbf{g})$ & $5.468 \pm 3.54$ & $35.650 \pm 3.54$ & $17.210 \pm 3.54$ \\
\hline TSS $\left(\right.$ Brix $\left.^{\circ}\right)$ & $7.950 \pm 2.67$ & $17.364 \pm 2.67$ & $12.645 \pm 2.67$ \\
\hline
\end{tabular}

Table 2. Correlation of studied traits among 22 jujube genotypes (Values in bold are significant at $P<0.05$ )

\begin{tabular}{|l|c|c|c|c|c|c|c|c|}
\hline Variables & FW & FL & FD & SW & SL & SD & PW & TSS \\
\hline Fruit weight (g) & $\mathbf{1}$ & & & & & & & \\
\hline Fruit length $(\mathbf{c m})$ & 0.568 & $\mathbf{1}$ & & & & & & \\
\hline Fruit diameter(cm) & $\mathbf{0 . 9 6 2}$ & 0.420 & $\mathbf{1}$ & & & & & \\
\hline Seed weight (g) & $\mathbf{0 . 8 1 7}$ & 0.418 & 0.742 & $\mathbf{1}$ & & & & \\
\hline Seed length (cm) & 0.350 & 0.757 & 0.177 & 0.558 & $\mathbf{1}$ & & & \\
\hline Seed diameter (cm) & 0.560 & 0.195 & 0.512 & $\mathbf{0 . 8 6 8}$ & 0.585 & $\mathbf{1}$ & & \\
\hline Pulp weight $(\mathbf{g})$ & $\mathbf{0 . 9 9 9}$ & 0.571 & $\mathbf{0 . 9 6 4}$ & 0.795 & 0.332 & 0.533 & $\mathbf{1}$ & \\
\hline TSS (Brix $^{\circ}$ ) & -0.017 & -0.490 & 0.064 & -0.037 & -0.473 & 0.015 & -0.016 & $\mathbf{1}$ \\
\hline
\end{tabular}

Abbreviations: FW: fruit weight, FL: fruit length, FD: fruit diameter, SW: seed weight, SL: seed length, SD: seed diameter, PW: pulp weight, TSS: total soluble solids 


\section{PCA plot analysis of genotypes}

Scattering pattern of all genotypes on principal component plot showed high level of diversity for studied morphological traits. Cumulative diversity in genotypes was $75.42 \%$ covered in first two principal components as shown Fig. 1. The genotypes in plan $\mathrm{B}$ and $\mathrm{C}$ are more diverse for their spread away from center of planes. The least spread genotypes were present in plan D, showing less narrow genetic base. Genotypes in plan A could successfully crossed with genotypes in plan D to get diverse lines in breeding and variety improvement program. Similarly, accessions in plan B and C had potential to be crossed to get diverse lines and screen out elite lines for cultivation.

Results proved broad genetic base in all 22 genotypes that could be utilized in breeding and variety improvement progam of jujube germplasm of desert zones of Bahawalpur to address its salinity and drought stresses for high quality fruit production. These results are in line with the finding of Saran et al. [14], who studied the broad genetic base in Indian jujube for various morphological traits.

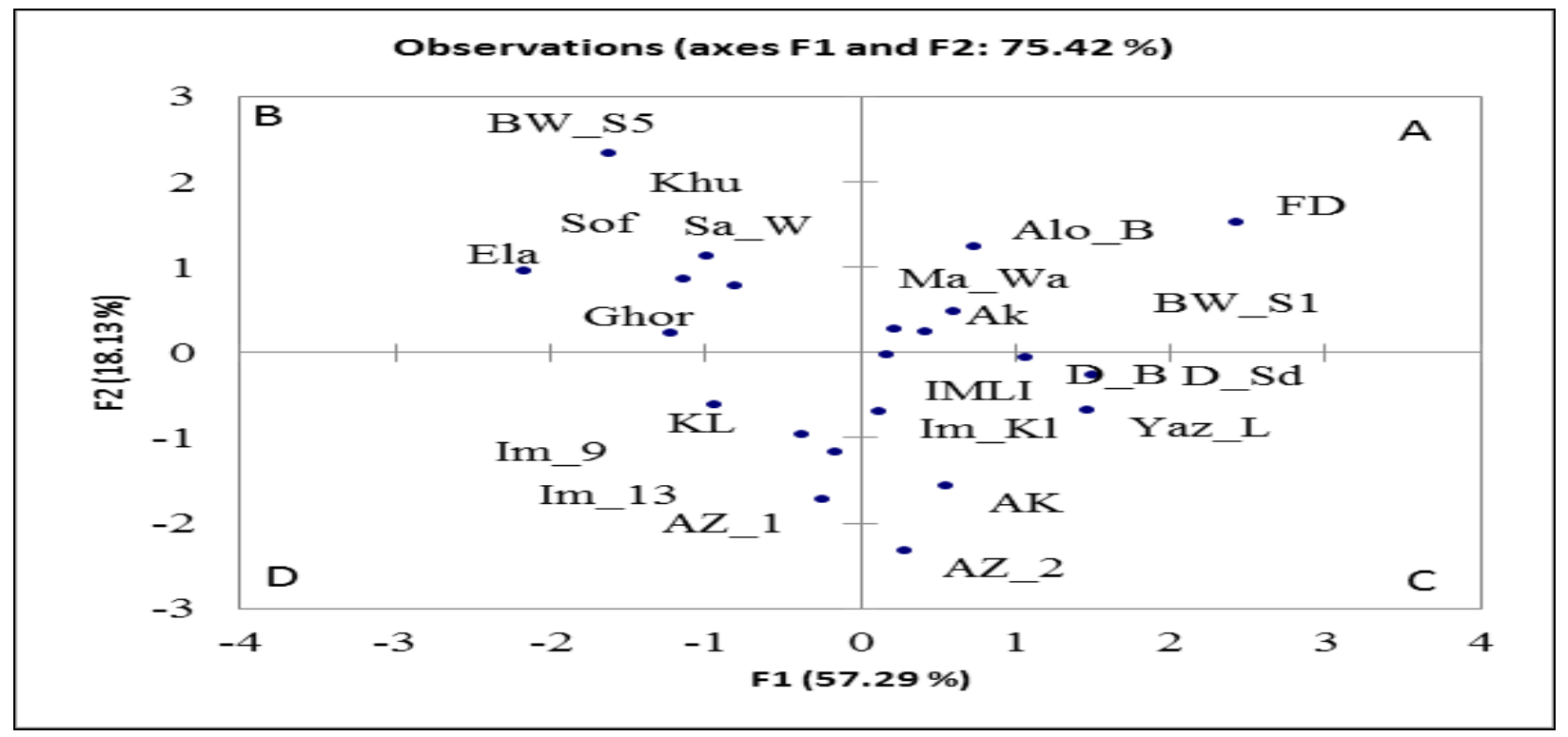

Figure 1. Spreading of 22 genotypes in PCA planes at $(P \leq 0.05)$ Bahawalpur selection-1 (BW_S1), Bahawalpur selection-5 (BW_S5), Yazman Local (Yaz_L), Sabir-Wali (Sa_W), Foladi (FD), Kerala (KL), Alobukhara (Alo_B), Dil-Bahar (D_B), Imran Kerala (Im_Kl), Anokhi (Ak), Ghor (Ghor), Khubani (Khu), Akasha (Ak), Sofan (Sof), Dehli Sofaid (D_sd), AZRI-1 (Az_1), AZRI-2 (Az_2), Elachi (Ela), Imran-9 (Im_9), (Imran-13 (Im_9), Mahmood Wali (Ma_Wa) and Imli (IMLI)

\section{Phylogenetic relation among selected genotypes}

All 22 genotypes are clustered into three main classes with maximum variation of $163 \%$ within class (c) followed by classes ( $a$ and $b$ ) with variation of 73.35 and $64.18 \%$ within the classes, respectively (Fig. 2). There were 7 genotypes in class 'a' with one genotype (FD) in subclass (a-I) not clustered with rest of the genotypes of this class showed highest diversity for various morphological traits. In subclass 'a-II' two genotypes (BW_SI and AK) share the fruit traits, however, they dissimilar from other genotypes (D_B, Alo_B, Yaz_L and D_sd) which had non-significant difference for fruit traits as shown in Fig. 2. Class (b) is biggest cluster with maximum genotypes (12) successfully grouped in this class with two subclasses containing three branches. The genotypes (Sof, IMLI-I, Khu and Ma_Wa), (Im_9, Im_13, KL, Az_2) and 
Im_KI, Sa_W and Ak) were grouped in same cluster showing similar genetic base for various fruit and seed characters. Class 3 (C) is smallest group with only three accessions, among which two (Ghor and Ela) are grouped and proved high level of similarities with accessions BW_S5 not clustered in this class showing diverse characters.

The tested 22 jujube genotypes were successfully grouped in different classes and proved the sharing of genetic makeup and reproducing morphological traits among each other. Saran et al. [14], Sehrawat (2006) [13], Singh [12] and Wang [11] stated similar results with broad genetic base in Indian jujube for various morphological traits, clustered all genotypes in different groups and suggested to develop useful breeding materials for jujube improvement from these clusters.

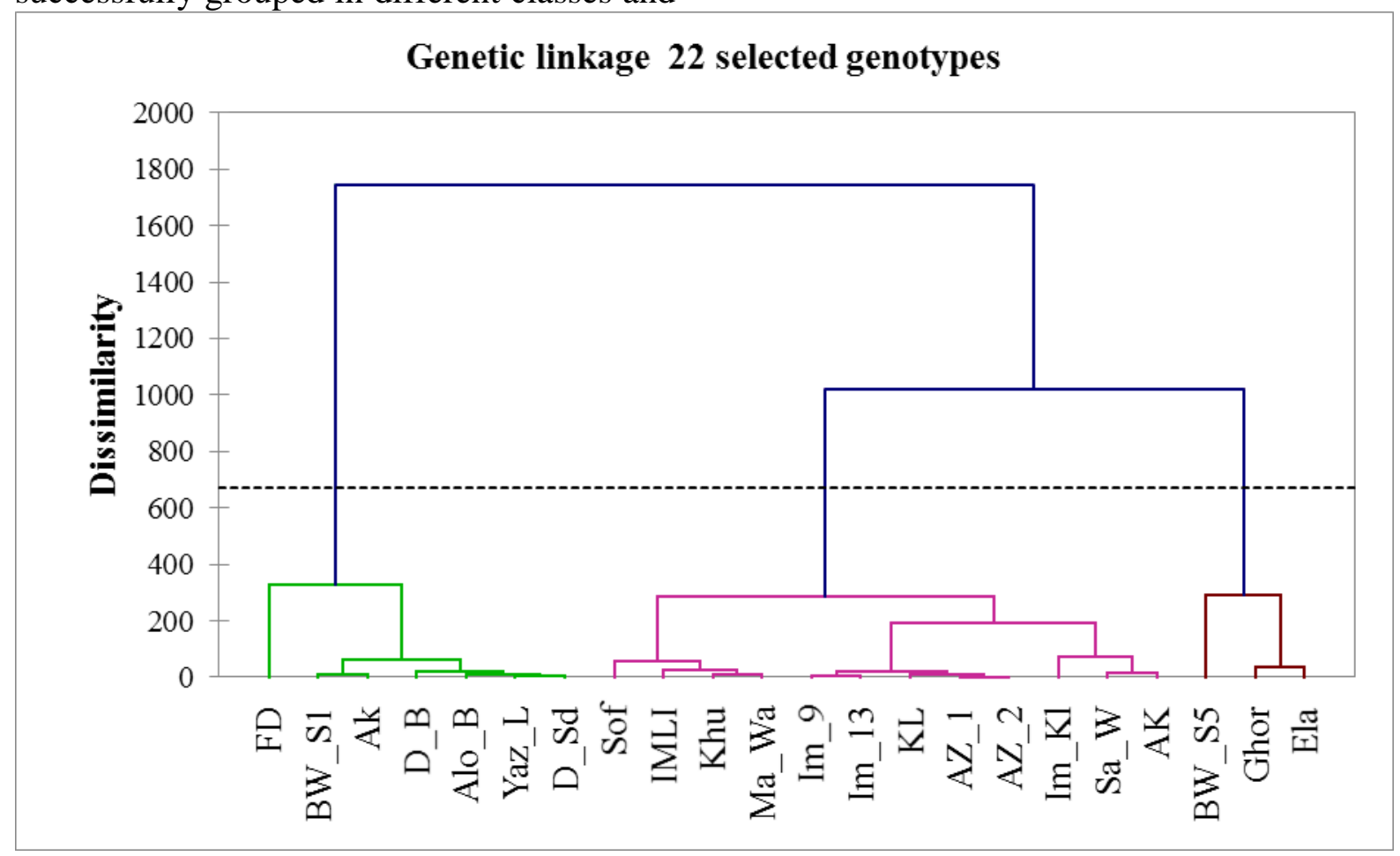

Figure 2. Genetic linkage among 22 selected genotypes

Bahawalpur selection-1 (BW_S1), Bahawalpur selection-5 (BW_S5), Yazman Local (Yaz_L), Sabir-Wali (Sa_W), Foladi (FD), Kerala (KL), Alobukhara (Alo_B), Dil-Bahar (D_B), Imran Kerala (Im_Kl), Anokhi (Ak), Ghor (Ghor), Khubani (Khu), Akasha (Ak), Sofan (Sof), Dehli Sofaid (D_sd), AZRI-1 (Az_1), AZRI-2 (Az_2), Elachi (Ela), Imran-9 (Im_9), (Imran-13 (Im_9), Mahmood Wali (Ma_Wa) and Imli (IMLI).

\section{Conclusion}

The present study has shown that the quantitative and qualitative traits of fruits are helpful to assess the diversity among the varieties of jujube. The results proved that the studied genotypes have a broad genetic base with a high flow of characters among them. Information in this manuscript could be used in selection breeding in varietal improvement programs.

\section{Acknowledgement}

The authors are thankful to the Regional Agriculture research institute, Bahawalpur and Arid Zone Agriculture Research Institute Bahawalpur Pakistan for providing fruit samples and logistic support for this study. 


\section{Authors' contributions}

Conceived and designed the experiments: Ishtiaq Ahmad \& Muhammad Nafees, Performed the experiments: Irfan Ashraf \& Maryam, Analyzed the data and edited manuscript: Jameel M. Al-Khayri \& Muhammad Nafees, Contributed reagents/ materials/ analysis tools: Malik Muhammad Yousaf \& Bashir Ahmad, Wrote the paper: Rahmatullah Qureshi \& Ishtiaq Ahmad.

\section{References}

1. Razi MF, Anwar R, Basra SMA, Khan MM \& Khan IA (2013). Morphological characterization of leaves and fruit of jujube (Ziziphus mauritiana Lamk.) germplasm in Faisalabad, Pakistan. Pak J Agric Sci 50: 211-216.

2. Ivanova AS (1982). Comparative characteristics of the quality composition of some stone fruits and subtropical fruit crops [In Russian] Bulleten Gosudarstvenngo Nikitskogo Botanicheskogo Sada. 47: 93-98.

3. Cherry M (1985). The Needs of the People. In: Wickens GE, Goodin JR \& Field DV (Ed.). Plants for Arid Lands. Unwin Hyman, London, UK.

4. Anonymous (2011). Economic Survey of Pakistan. Government of Pakistan, Ministry of Food and Agriculture, Islamabad, Pakistan.

5. Sharif N, Jaskani MJ, Memon N, Alwi M, Baloch DM, Abbas MM \& Ishfaq M (2013). Categorization of Ber varieties in relation to blooming period, fruit setting and harvesting time. Pak J Agric Sci 50(3): 407-413.

6. Bal JS (1992). Identification of Ber (Zizyphus mauritiana Lamk.) Cultivars through vegetative and fruit characters. Acta Hortic 317:245-254.

7. Reich MR \& Scorza R (1995). Aberrent transmission of RAPD markers in haploid, doubled haploids and F1 hybrids of Peach: observations and speculation on causes. Sci Hortic 64: 233-241.

8. Ghosh SN \& Methew B (2002). Performance of nine Ber (Ziziphus mauritiana Lamk) cultivars on topworking in the semi-arid region of West Bengal. J Appl Hort 4(1): 49-51.

9. Preeti \& Tripathi S (2014). Ziziphus jujube: A phyto-pharmacological review. Int J Res Develop Pharm Life Sci 3(3): 959-966.

10. Ketipearachchi, Gamlath KW, JGKL \& Wijethunga KGNAB (2015). Diversity of morphological characteristics of Ziziphus mauritiana Lam. Indian jujube and Ziziphus jujube Mill. Chinese jujube in Sri Lanka. Ann Sri Lanka Dept Agri 17: 355-358.

11. Wang YK, Li DK, Sui CL \& Du XM (2009). Conservation, characterization, evaluation and utilization of Chinese jujube germplasm resources. Acta Hort 840: 235-240.

12. Singh AK, Sharma RK, Singh NK, Bansal KC, Koundal KR \& Mohapatra $T$ (2006). Genetic diversity in ber (Ziziphus spp.) revealed by AFLP markers. J Hort Sci Biotechnol 81: 205-210.

13. Sehrawat SK, Boora KS, Dahiya DS, Ahlawat VP \& Goyal RK (2006). DNA finger printing of Ber (Ziziphus mauritiana Lamk) germplasm. Haryana J Hort Sci 35(3/4): 213-214.

14. Saran PL, Godara AK, Sehrawat SK, Dahiya DS. (2006). Characterization of Ber (Ziziphus mauritiana Lamk.) genotypes. Haryana J Hort Sci 35(4): 215-218. 